\title{
Time to detection of anemia and its predictors among children living with HIV at Debre Tabor and University of Gondar Compressive Specialized Hospitals, 2020: a multicentre retrospective follow-up study
}

Ermias Sisay Chanie ${ }^{1 *}$, Dejen Getanh Feleke ${ }^{1}$, Sintayehu Asnakew², Fisha Alebel GebreEyesus ${ }^{3}$, Aragaw Tesfaw ${ }^{4}$, Wubet Alebachew Bayih ${ }^{5}$, Agimasie Tigabu ${ }^{6}$, Yared Asmare Anyalem7, Abraham Tsedalu Amare ${ }^{6}$,

Demeke Mesfin Belay ${ }^{1}$, Fentaw Teshome Dagnaw ${ }^{4}$ and Biruk Beletew Abate ${ }^{8}$

\begin{abstract}
Background: Even though antiretroviral therapy access for HIV infected children increased dramatically, anemia have been continued as a challenge regardless of a cluster of differentiation (CD4) count and viral load. Hence, this study aimed to assess the time to detection of anemia and its predictors among children living with HIV at Debre Tabor and university of Gondar compressive specialized hospital, 2020.

Methods: A retrospective follow-up study was conducted from January 2010 to December 2018. A total of 372 children under the age of 15 who had received ART were included in the study. Data were collected from children's medical charts and ART registration logbook using a standard checklist. Besides, the data were entered into Epi data 4.2.2 and then exported to Stata 14.0 for further analysis. The Cox regression model, the variables having $P$-value $\leq .05$ with $95 \% \mathrm{Cls}$ in multivariable analysis were declared as statistically significant for anemia.
\end{abstract}

Result: The mean $( \pm \mathrm{SD}$ ) of follow-up periods were $56.6 \pm 1.7$ SD months. The overall median survival time free from anemia was 137 months, and the incidence rate of anemia was 6.9 per $100 \mathrm{PYO}$ (95\% Cl: 5.3, 7.8). Moreover, WHO clinical staging of III/IV [AHR: 4.2, 95\% Cl: 1.80, 11.1], low CD4 count below threshold [AHR: 1.9, 95\% Cl: 1.09, 3.37], cotrimoxazole preventive therapy non-users, and poor level of adherence [(AHR: 2.4, 95\% Cl: 1.20, 4.85] were the main predictors of the time to detection of anemia.

(Continued on next page)

\footnotetext{
* Correspondence: ermisis1888@gmail.com

'Department of Pediatrics and Child Health Nursing, College of Health

Sciences, Debre Tabor University, Debre Tabor, Ethiopia

Full list of author information is available at the end of the article
}

C C The Author(s). 2021 Open Access This article is licensed under a Creative Commons Attribution 4.0 International License, which permits use, sharing, adaptation, distribution and reproduction in any medium or format, as long as you give appropriate credit to the original author(s) and the source, provide a link to the Creative Commons licence, and indicate if changes were made. The images or other third party material in this article are included in the article's Creative Commons licence, unless indicated otherwise in a credit line to the material. If material is not included in the article's Creative Commons licence and your intended use is not permitted by statutory regulation or exceeds the permitted use, you will need to obtain permission directly from the copyright holder. To view a copy of this licence, visit http://creativecommons.org/licenses/by/4.0/. The Creative Commons Public Domain Dedication waiver (http://creativecommons.org/publicdomain/zero/1.0/) applies to the data made available in this article, unless otherwise stated in a credit line to the data. 
(Continued from previous page)

Conclusion: The incidence rate of anemia in our retrospective cohort was high. The risk of anemia is present in children living with HIV infection but the risk for anemia is increased based on (WHO clinical staging III and IV, CD4 count below the threshold level, CPT non-users, and poor level of adherence). Since many of these risk factors are present routinely, even within one single patient, our clinical monitoring for anemia quarterly was fully justified as was our routine switch from standard therapies such as AZT to another regimen upon lab confirmation of anemia. Additional methods to improve cotrimoxazole preventative therapy and level of adherence are also needed.

Keywords: Time to detection, Anemia, Predictors, Children, ART, Ethiopia

\section{Background}

Hematological abnormalities are a common and independent poor prognostic marker of HIV disease [1, 2], which worsens quality of life [3], and decreases survival [4]. Moreover, hematological abnormalities, mainly anemia has been continued as a challenge in resource limited setting [5].

Anemia is the commonest disorder that is seen among HIV infected children [6]. WHO estimates that over 2 billion people are anemic worldwide, of these, more than 100 million anemic children were living in Africa [7]. Even though ART access for HIV infected children increased dramatically, side effects have continued after the initiation of therapy predominantly in resourcelimited setting [3]. Besides, anemia has been a strong risk factor for disease progression and subsequent death regardless of a cluster of differentiation (CD4) count and viral load $[4,8]$.

Hematological abnormalities have been documented as the second cause of morbidity and mortality in HIVinfected children living in resource-limited countries [9]. Indeed, anemia is common [10]. Anemia is the leading hematologic complication of HIV infection occurring in approximately $30 \%$ of patients with an asymptomatic infection and as many as $75-80 \%$ of those with Acquired immunodeficiency disease (AIDS) [11], particularly in children whose immune systems are not yet fully developed [12]. Additionally, children are the most vulnerable population for anemia, it is responsible for a high proportion of HIV-related deaths each year [7], up to $90 \%$ of children develop anemia during HIV infection [13].

Anemia is a leading cause of hospital admission, reduced cognitive development, growth, and poor immune function in children [7]. since the etiology and pathogenesis of anemia are complex [14] and may be caused by a multitude of factors such as cancer, micronutrient deficiencies; infections, such as malaria and tuberculosis (TB) [15]. In HIV-infected children, the virus can infect parts of the bone marrow responsible for manufacturing red blood cells and erythropoietin, which is required to stimulate red blood cell production [16]. In addition, the antiretroviral medication causes and exacerbates anemia due to bone marrow suppression [17].
Giving attention to the young age of children [18] and children with unemployment parent [19], have been risk factors identified in the past with an impact on HIV associated anemia. Moreover, children with viral load > 1000 copies/ml [9, 20], low CD4 count <200cells/ul [21, 22], and WHO stage III/IV) [7, 20, 23], have been risk factors reported in the previous study.

Despite the above prevention and management approach that has been implemented in Ethiopia, the burden of anemia in HIV infected children is still unacceptably high. Anemia has attracted the attention of both government and researchers since there has been no prior study on time to detection of anemia and its predictors among HIV infected children in the country in general and in the study area in particular. Hence, this study aims to assess the time to detection of anemia and its predictors among children living with HIV at Debre Tabor and university of Gondar compressive specialized hospitals.

\section{Methods \\ Study design and period}

A retrospective follow-up study was conducted from January 1, 2010-December 30, 2018, at Debre Tabor and university of Gondar compressive specialized hospitals.

\section{Study setting}

Debre Tabor compressive specialized hospital is the largest hospital in South Gondar Zone which provide in outpatient, inpatient and operation theatre department. The hospital has been provided service for a population of 2.4 million including ART services. The university of Gondar hospital is a 400-bed hospital and the regional referral center for the for four district hospitals in the area. The hospital services about four million across the region

\section{Source population}

All children < 15 years living with HIV at Debre Tabor and university of Gondar comprehensive specialized hospitals. 


\section{Study population}

All children $<15$ years living with HIV from January 1, 2010-December 30, 2018, at Debre Tabor and university of Gondar Compressive specialized hospitals.

\section{Inclusion criteria}

All children < 15 years living with HIV from January 1, 2010-December 30, 2018, at Debre Tabor and university of Gondar compressive specialized hospitals.

\section{Exclusion criteria}

Medical charts and ART registration logbook of the study participants with incomplete outcome (i.e., hemoglobin status not recorded) variables were excluded.

\section{Sample size and sampling procedure}

The sample size was calculated by using Log-rank survival data analysis of the two-population proportion formula based on the following important assumptions- 95\% confidence level, $80 \%$ optimum statistical power, and taking type one error $5 \%$. By considering a study was conducted in eastern Ethiopia [24], by taking sex as a predictor variable (on the male as the exposed group denoted by q1 (0.38) and female group denoted by q0 (0.53), and then the total sample size, after adding $10 \%$ as incomplete medical records, and the final sample size was 372 .

A total of 372 children who started ART during the study period were identified in the pediatric ART clinics, the investigator assigned the registration numbers from January 1, 2010, to May 30, 2020, in chronological order. Of these, the investigator drew 357 samples that fulfilled the inclusion criteria after reviewing the medical charts and ART registration logbook; and then 15 medical records did not fulfill the inclusion criteria were excluded (Fig. 1).

The dependent variable of this study is time to anemia, whereas age caregivers, sex caregivers, age child, sex child, educational status caregivers, marital status caregivers, occupation caregivers, religion caregivers, residence child, relationship to the child, ART regimen, duration of ART, level of adherence, OI prophylaxis (IP\& CPT), developmental milestone/Functional status, treatment failure, history of TB, WHO clinical stage, CD4 count/percent, nutritional status (WGT-Age, WGT-H \&HT-Age), and history of OI were independent variables.

\section{Operational definitions \\ Time to detection of anemia}

time calculated by subtracting dates from children ART initiation to the occurrence of the event (i.e., anemia) during the follow-up period.

\section{Censored}

A study participants who were lost to follow-up, transfer to another service, and end of the study period before developing anemia were considered as censored.

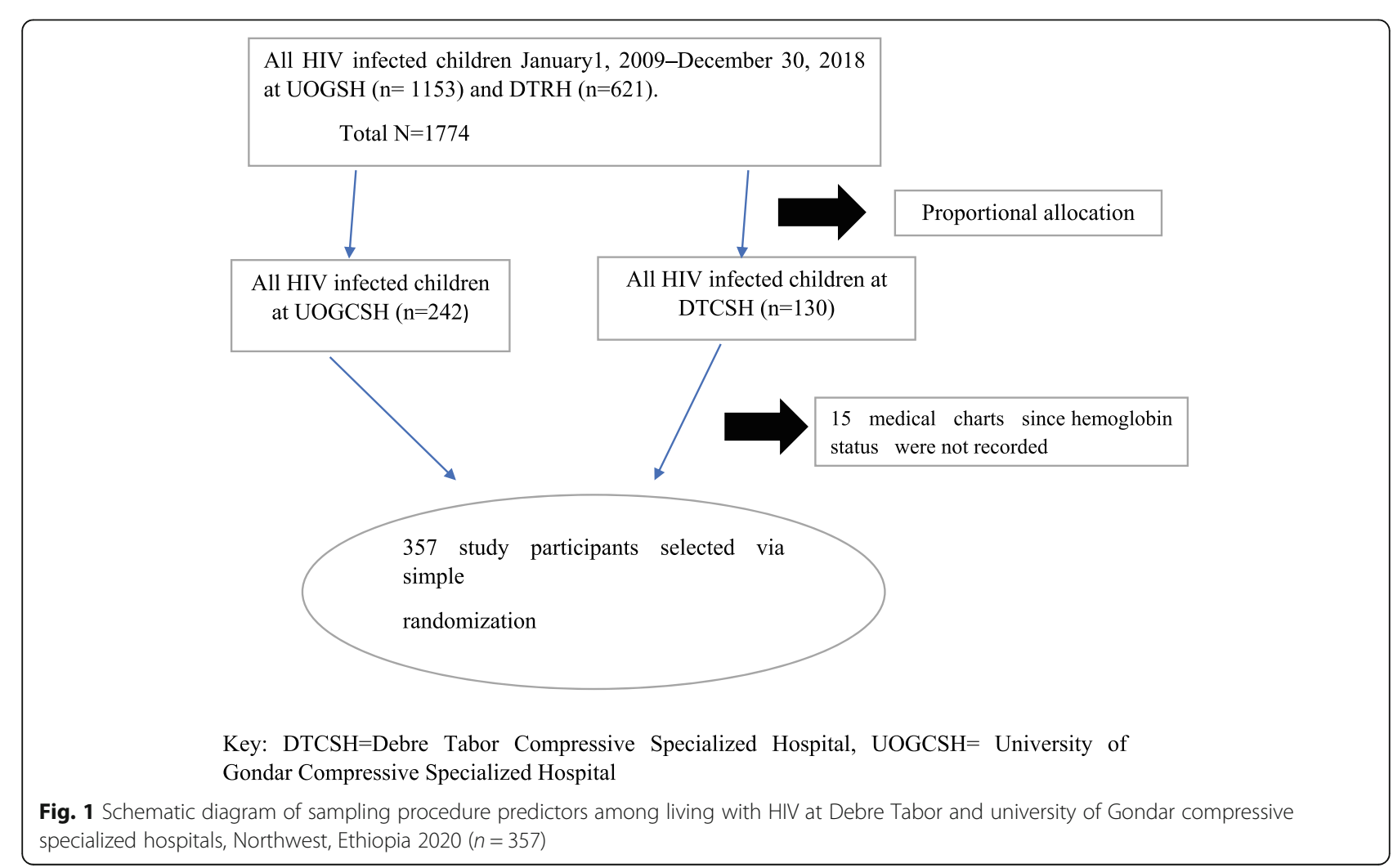




\section{Anemia definitions by age}

The hemoglobin level less than $11 \mathrm{~g} / \mathrm{dl}$ for children $<5$ years old, $<11.5 \mathrm{~g} / \mathrm{dl}$ for children $5-11.9$ years old, and < $12 \mathrm{~g} / \mathrm{dl}$ for children $12-14.9$ years old [13].

\section{Diagnosis of TB}

TB is diagnosis by using strong clinical suspicion, laboratory tests, or X-ray examination.

\section{General treatment algorithm if anemia occurred}

The hemoglobin status of children livening with HIV were monitored every 03 months regularly. However, if they have clinical suspicion, their hemoglobin was checked regardless of the time. If the hemoglobin level is low based on the above reference age group, the treatments are given including regimen change like Stavudine replaced zidovudine if a child had a $\mathrm{Hb}<8 \mathrm{~g} / \mathrm{dl}$, iron supplementation. In addition to this, blood transfusion was also given if the hemoglobin level $<4 \mathrm{mg} / \mathrm{dl}$.

Underweight or stunting was defined as weight for age Z-score $<-2$ Standard deviation (SD) under-five children and BMI (Body Mass Index) for age Z-score < - 2 SD for older children [25].

ART adherence: defined as good, fair, or poor by the percentage of drug dosage calculated from the total monthly doses of ART drugs taking (Good >95\%, fair 85-94\%, poor < 85\%) [26].

Treatment failure classified as clinical, immunological and virological failure. Clinical failure: indicating advanced or severe immune deficiency (WHO clinical stage 3 and 4 clinical condition with exception of TB) after 6 months of effective treatment, Immunological failure: Persistent (at least 2 CD4 measurements) CD4 levels below 200cells $/ \mathrm{mm}$ for children younger than 5 years and, CD4 levels below 100 cells $/ \mathrm{mm}$ for older than 5 years, and Virological failure, the Viral load above 1000 copies/mL based on two consecutive viral load measurements in 3 months [27, 28].

The first-line ART regimen comprised the nucleoside reverse transcriptase inhibitors usually zidovudine (AZT) in the study setting during the study period. However, AZT or another regimen can change by another drug include drug-resistant viral isolates, anemia, or other adverse outcome based on the laboratory's investigation or the healthcare providers decision in the study setting. Such as, AZT replaced by Stavudine if a child had a hemoglobin $<8 \mathrm{~g} / \mathrm{dl}$. Additionally, Efavirenz replaced nevirapine if a child was on concurrent treatment for tuberculosis with rifampicin.

\section{Cotrimoxazole preventative therapy (CPT)}

CPT is a feasible, inexpensive, and well-tolerated way of using cotrimoxazole intervention in PLWHA to reduce HIV/AIDS-related morbidities and mortalities caused by various bacteria, fungi, and protozoa. Cotrimoxazole suspension contains $200 \mathrm{mg} / 40 \mathrm{mg}$ per $5 \mathrm{ml}$ of syrup. Single strength tablets contain $400 \mathrm{mg} / 80 \mathrm{mg}$, double-strength tablet twice that. It is possible to divide the tablets for children and infants [29, 30].

\section{WHO stages I - IV}

According to the Ethiopian ART guidelines, the WHO stages I - II OIs includes Asymptomatic infection, Herpes zoster, and Persistent generalized lymphadenopathy. In addition, the WHO stages III-IV OIs includes unintentional weight loss of more than $10 \%$ body weight, recurrent upper respiratory tract infections, chronic diarrhea > 1 month, Prolonged fever > 1 month, Oral candidiasis, TB, HIV wasting syndrome, Pneumocystis carinii (juvenii) pneumonia (PCP), Toxoplasmosis of the brain, Extrapulmonary tuberculosis, Kaposi's sarcoma, and HIV encephalopathy [31-33].

\section{Data collection tools and procedures}

Data extraction tool was derived from a standard national HIV follow-up form of Ethiopia. Data were extracted from medical charts and ART registration logbook in terms of socio-demographic variables of the children and parents/caregivers contained 10 items. Likewise, clinical and treatment-related variables, which contained a total of 12 items were extracted from medical charts and ART registration logbook. The three nurses, experienced in ART clinic practice collected the data for the study and all were duly qualified with university degrees.

\section{Data quality control}

A Pretest was conducted among 19(5\%) of the sample size in medical records to check the consistency of the abstraction tools at University of Gondar comprehensive specialized hospital. Two days of training were given about the objectives, significance, and variables of the research for 03 data collectors and 02 supervisors. All data collectors and supervisors were given basic training and mentorship in ART. The filled formats were checked for completeness by the supervisor, data cleaning and double data entry were carried out to check for any inconsistencies, coding errors, missing or out of range values.

\section{Data processing and analysis}

Data were entered into Epi data 4.2.2 then exported to Stata version 14 for further analysis. Categorical data were presented as frequency and continuous data as the median and interquartile range (IQR). The incidence rate of anemia was calculated with children with anemia as the numerator divided by total child-months. The cumulative probability of anemia was estimated using the 
Kaplan-Meier failure method and the survival curves were compared between the predictor variable by the log-rank test. In Cox regression analysis, variables having a $p$-value $\leq 0.25$ were entered into multivariable and the variables having $\leq .05$ in multivariable were declared as statistically significant for anemia. Additionally, the model and the variable were tested via graphic and numerical assessment (global test $=0.644$ ).

\section{Results}

\section{Socio-demographic characteristics}

Out of 372 records, 357 pediatric ART records with a completeness response rate of $95.9 \%$ were reviewed and 15 of the medical records were excluded from the study. The median age of children and caregivers was 7.3(SD + $-0.28)$ and $34.9(\mathrm{SD}+-0.37)$ years, respectively. More than half the children 184(51.5\%) were male, whereas 193(54.1\%) caregivers were female. About 285(79.8\%) of the caregivers had urban residences and 249(69.7\%) were married. The majority of the caregivers $302(84.6 \%)$ were orthodox Christian; likewise, 330 were Amara ethnic group. Moreover, 147(41.2\%) and 193(54.1\%) of the caregivers were uneducated and unemployed, respectively, and 203(56.9\%) of the children were enrolled before a test and treat strategies (Table 1).

\section{Clinical and treatment related characteristics}

A total of $70(19.6 \%)$ and $111(31.1 \%)$ of children had CD4 counts below the threshold level and WHO clinical III and IV, respectively. Forty-one (11.5\%) had tuberculosis and $181(50.7 \%)$ had a history of opportunistic infection in the follow-up period. The majority $309(86.6 \%)$ of children were on a zidovudine-containing regimen contain, and 291(81.5\%) had taken Cotrimoxazole preventive therapy. Only 109 (30.5\%) had taken isoniazid preventive therapy. Regarding nutrition, 182(59.1\%) and $146(40.9 \%)$ of the children were underweight and stunted, respectively. Thirty-six (10.15) of the children had treatment failure, and 199(55.7\%) of the children were $<60$ months on ART (Table 2).

Table 1 Socio demographic characteristics among children living with HIV at Debre Tabor and university of Gondar Compressive Specialized Hospitals, Northwest, Ethiopia $2020(n=357)$

\begin{tabular}{|c|c|c|c|}
\hline Exposure variable & Responses & Frequency $(n=357)$ & Percent (\%) \\
\hline \multirow[t]{2}{*}{ Age of the Caregiver's } & $\leq 34$ years & 216 & 60.5 \\
\hline & $>34$ years & 141 & 39.5 \\
\hline \multirow[t]{2}{*}{ Sex Caregiver's } & Male & 164 & 45.9 \\
\hline & Female & 193 & 54.1 \\
\hline \multirow[t]{2}{*}{ Age of the child (years) } & $\leq 7$ & 178 & 49.9 \\
\hline & $>7$ & 179 & 50.1 \\
\hline \multirow[t]{2}{*}{ Sex } & Male & 184 & 51.5 \\
\hline & Female & 173 & 48.5 \\
\hline \multirow[t]{2}{*}{ Residence } & Rural & 72 & 20.2 \\
\hline & Urban & 285 & 79.8 \\
\hline \multirow[t]{3}{*}{ Caregiver's Marital status } & Married & 249 & 69.7 \\
\hline & Widowed & 37 & 10.4 \\
\hline & Divorced & 71 & 19.9 \\
\hline \multirow[t]{3}{*}{ Ethnicity } & Amhara & 338 & 94.7 \\
\hline & Tigray & 17 & 4.8 \\
\hline & Others & 2 & 0.6 \\
\hline \multirow[t]{3}{*}{ Religion } & Orthodox & 302 & 84.6 \\
\hline & Muslim & 49 & 13.7 \\
\hline & Other $^{\mathrm{a}}$ & 6 & 1.7 \\
\hline \multirow[t]{4}{*}{ Caregiver's educational status } & No education & 147 & 41.2 \\
\hline & Primary education & 92 & 25.8 \\
\hline & Secondary education & 96 & 26.9 \\
\hline & Tertiary education & 22 & 6.2 \\
\hline \multirow[t]{2}{*}{ Caregiver's Occupation } & Non employed & 193 & 54.1 \\
\hline & Employed & 164 & 45.9 \\
\hline
\end{tabular}


Table 2 Clinical and treatment related characteristics among children living with HIV at Debre Tabor and university of Gondar compressive specialized hospitals, Northwest, Ethiopia $2020(n=357)$

\begin{tabular}{|c|c|c|c|}
\hline Exposure variable & Responses & Frequency $(n=357)$ & Percent (\%) \\
\hline \multirow[t]{2}{*}{ Weight for height } & Normal & 175 & 49.0 \\
\hline & Underweight & 182 & 59.1 \\
\hline \multirow[t]{2}{*}{ Height for age } & Normal & 211 & 59.1 \\
\hline & Stunted & 146 & 40.9 \\
\hline \multirow[t]{2}{*}{ CD4 counts or $\%$} & Below threshold & 70 & 19.6 \\
\hline & Above threshold & 287 & 80.4 \\
\hline \multirow[t]{2}{*}{ WHO stages } & Stage I\&\| & 244 & 68.3 \\
\hline & Stage III\&IV & 111 & 31.1 \\
\hline \multirow[t]{2}{*}{$\mathrm{Hx}$ of Ols } & Yes & 181 & 50.7 \\
\hline & No & 176 & 49.3 \\
\hline \multirow[t]{2}{*}{ Regimen at baseline } & AZT-based & 309 & 86.6 \\
\hline & d4T-based & 48 & 13.4 \\
\hline \multirow[t]{2}{*}{ Cotrimoxazole preventive therapy (CPT) } & Yes & 291 & 81.5 \\
\hline & No & 66 & 18.5 \\
\hline \multirow[t]{2}{*}{ Isoniazid preventive therapy (IPT) } & Yes & 109 & 30.5 \\
\hline & No & 248 & 69.5 \\
\hline \multirow[t]{2}{*}{ ART adherence } & Good & 278 & 77.9 \\
\hline & Fair & 31 & 8.7 \\
\hline \multirow[t]{2}{*}{ Treatment failure } & Poor & 48 & 13.4 \\
\hline & Yes & 36 & 10.1 \\
\hline \multirow[t]{2}{*}{ TB status } & No & 321 & 89.9 \\
\hline & Yes & 41 & 11.5 \\
\hline \multirow[t]{2}{*}{ ART duration } & No & 316 & 88.5 \\
\hline & $<=5$ years & 199 & 55.7 \\
\hline \multirow[t]{2}{*}{ Follow-up status Anemia } & $>5$ years & 158 & 44.3 \\
\hline & Yes & 58 & 16.2 \\
\hline
\end{tabular}

CD4 cluster of differentiation 4, WHO World Health Organization, Ols opportunistic infections, AZT azidothymidine or Zidovudine, and d4T: stavudine

\section{The median survival time to develop anemia during the} follow-up period

The mean follow-up periods were $56.6 \pm 1.7$ SD months, overall yielding 20,191 child-month observations. At the end of follow-up, 58[16.5, 95\% CI: 12.8 to $20.4 \%]$ of the children were anemia while $299(83.8 \%)$ of children were non-anemic. The incidence rate of anemia was 6.9 per 100 PYO (95\% CI: 5.3, 7.8). The overall median survival time of children free from anemia was 137 months (Fig. 2). The median survival time free from anemia among children who had a CD4 count below the threshold level was 62 months, but 125 months for those who had a CD4 count above the threshold level. The study revealed, the median survival time free from anemia was 70 months among children who had WHO stage III and IV, but 107 months for those WHO stage I and II in the follow-up period. The median survival time free from anemia among children who had zidovudine regimen were 60 months, while 140 months for those non-

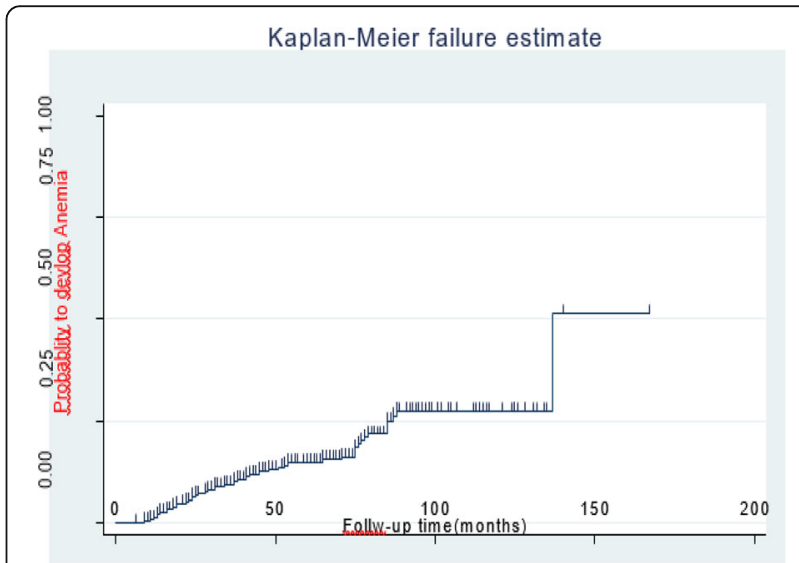

Fig. 2 Kaplan-Meier failure estimate of anemia among children living with HIV at Debre Tabor and university of Gondar compressive specialized hospital, Northwest, Ethiopia $2020(n=357)$ 
zidovudine regimens contained to in the follow-up period (Fig. 3). Log rank survival curve comparisons of the associated predictor variables were estimated. Besides, the Cox-Snell residual nelson- Alen cumulative hazard graph for the goodness of model fitness also evaluated (Fig. 4).

In Cox proportional hazard model bivariable analysis including sex of caregivers, occupation of caregivers, test and treat strategies, weight for age, height for age, TB status, regimen type, CPT, CD4 count threshold level, level of adherence, WHO clinical staging, and OI status were having $P$ value less than 0.25 for the occurrence of anemia and entered into the multivariable analysis. Besides, in multivariable models, WHO clinical staging III and IV, CD4 count below the threshold level, CPT nonusers, and poor level of adherence were associated with the time to detection of anemia.

The hazard of anemia in children who had WHO stage III and IV were 4.2 times higher as compared to children with WHO staging I and II [AHR: 4.2 (95\% CI: 1.80, 11.1)]. Besides, Children who had a CD4 count below the threshold level had an increased hazard of anemia of 1.9 times that of children with a CD4 count above the threshold level [AHR: 1.9 (95\% CI: 1.09, 3.37)]. Moreover, children who had cotrimoxazole preventive therapy non-users were 2.2 times higher the hazards of anemia than those who those cotrimoxazole preventive therapy users [AHR: 2.2 (95\% CI: 1.23, 3.82)], and children with

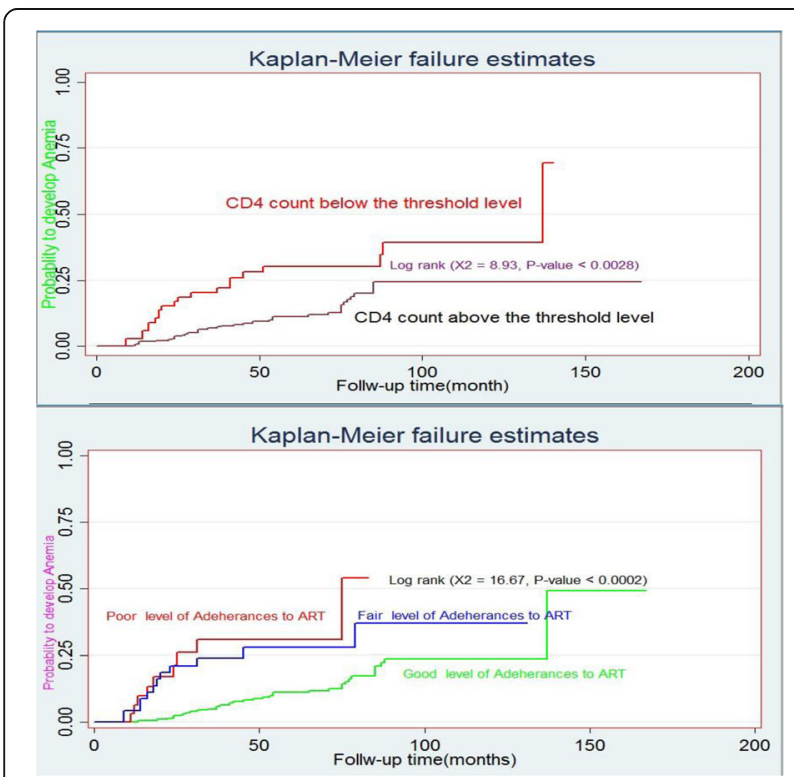

Fig. 3 Kaplan-Meier failure estimate of anemia of the main predictors among children living with HIV at Debre Tabor and university of Gondar compressive specialized hospitals, Northwest, Ethiopia $2020(n=357)$. Kaplan-Meier failure estimate of anemia of the main predictor variable among children living with HIV at Debre Tabor and university of Gondar compressive specialized hospitals, Northwest, Ethiopia $2020(n=357)$ a poor level of adherence have increased a hazard of anemia by 2.4 times as compared with children with a good level of adherence [(AHR: 2.4 (95\% CI: 1.20,4.85)] (Table 3).

\section{Discussion}

This study assessed the time to detection of anemia and its predictors among children living with HIV at Debre Tabor and university of Gondar compressive specialized hospital, Ethiopia. Almost one-in-six HIV infected children $(16.5 \%, n=58)$ with anemia were recorded in the follow-up period. The incidence rate of anemia was 6.9 per 100 child-years. Moreover, the median survival time was 137 months. WHO clinical staging III/IV, CD4 count below the threshold level, CPT non-user, poor adherence, and before test and treat strategies (pre-ART) were found to be the main predictors of anemia.

The rate of anemia in our study is $16.5 \%$ (95\% CI: 12.8 to $20.4 \%$ ), which is comparable with a study conducted in northwest Ethiopia, which were 19.8 and 12.26\% [34, 35], and also with Addis Ababa, Ethiopia, which was $17.59 \%$ [36]. This could be justified in two ways. Firstly, a cut-off value of Hgb to define anemia. Secondly, study participants had a similar age group (i.e.., children $<15$ years). In addition to this, it may be due to the data extraction tools of all studies were prepared from a standard HIV/AIDS Care and treatment guidelines ART service in Ethiopia.

However, The rate of anemia in our study is lower than studies conducted in India, where the incidence was $21.9 \%$ [37] and $47.1 \%$ [38] respectively., in Jimma, Ethiopia, was $21.9 \%$ [37], in Nigeria among aged between 5 and 12 years, was 54.2\% [39], in Cameron, was $49.6 \%$ [12], in South Africa, was 73\% [40], in Gahan 2091 among under 5 Years, was 53.8\% [41], Malawi, was 45.7\% [9], in Mozambique among 6-59 months of children, was $88 \%$ [7], in Kenya, was 35.9\% [23], and in Tanzania, was $27.7 \%$ respectively [19]. This difference could be due to the cut-off point of anemia, study design since most of the above studies were cross sectional, whereas our study was a cohort. In addition, the variations might be due to the difference in the study area, duration of time on ART, and differences in the followup periods. A shorter follow-up period is likely to find a higher probability of anemia when compared with a study with a longer follow-up period. Besides, the discrepancy may be due to monitoring of anemia every 3 months in our study area whereas more frequently in other settings. Likewise, the discrepancy may be due to the study participants (i.e., aged b/n 5-12 years and under 5 years).

Moreover, the finding of this study lower is lower than the study conducted among non-HIV negative children with some malaria endemic areas in Ethiopia [42-44]. 


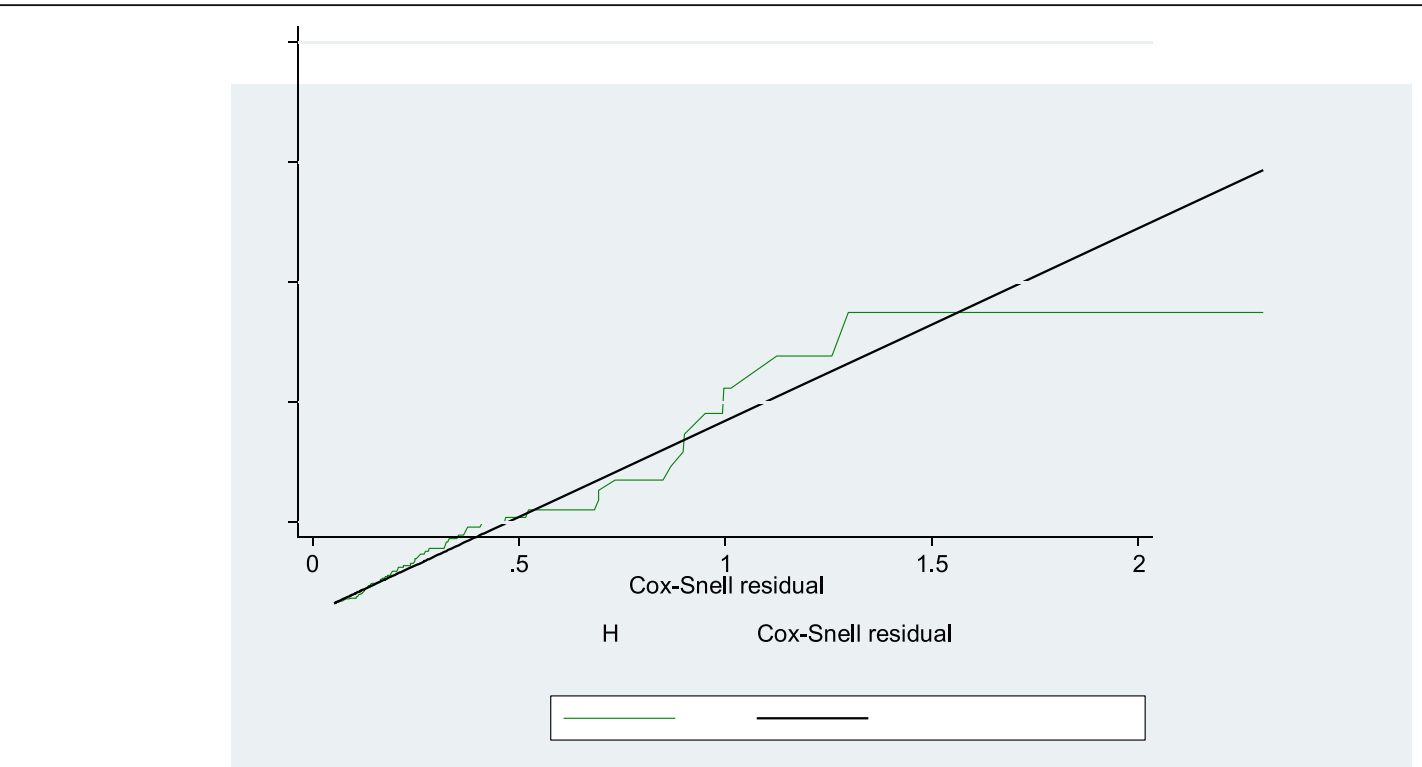

Fig. 4 Cox-Snell residual Nelson- Alen cumulative hazard graph for the goodness of model fitness which shows the hazard function follows the $45^{\circ}$ closeness among children living with HIV at Debre Tabor and university of Gondar compressive specialized hospital, Northwest, Ethiopia $2020(n=357)$

This discrepancy can be explained by malaria is a leading cause of anemia due to causes haemolysis of infected, uninfected erythrocytes rapidly [45, 46], but the study setting is not malaria endemic areas. On the other hand, the incidence rate of anemia has been observed in this study is higher than a study conducted in Hawassa Ethiopia, in 2018, which was $11.4 \%$ [47]. In the AsiaPacific region, between January 2003 and September 2013, severe anemia was 5.5\% [48], a study conducted from November 2007 to June 2009 in the region of Africa, $4.8 \%$ of children with severe anemia [20] in 2016 Uganda, Anemia was $11.8 \%$ among $12-14$ years respectively [49]. This difference could be explained by the differences in the outcome measurement, ethnicity, sample size, study design, and follow-up period. Moreover, the heterogeneity of the data inherent in a multinational cohort, the type's health care service, and study setting.

Children who were WHO clinical staging III and IV increased the hazard of anemia by 4.2 times as compared to children with WHO clinical staging I and II. The median duration of free from anemia was significantly shorter in persons with WHO clinical staging III and IV in the follow-up period. The finding is in line with a study from Mozambique, west Africa, and Kenya [7, 20, 23]. This may be due to having advanced WHO clinical staging which could compromise immunity and can lead to severe illness due to viral replication, depletion of CD4 count, and the added burden of disease. Moreover, children who had a CD4 count below the threshold level were increased the hazard of anemia by 1.9 times as compared to children with a CD4 count above the threshold level. The median survival time free from anemia was significantly longer in persons with a CD4 count above the threshold level. This finding was also supported by several studies conducted in Asia, Malawi, and Nigeria [3, 9, 39]. Moreover, the finding was also similar in a study conducted in Black Lion and Zewuidtu referral hospital in Ethiopia < 350 cells/ $\mu \mathrm{l}[21,22]$. This could be explained by low CD4 count elicited dysfunction of the immune system and increased vulnerability of the host to infection, immunological deficiency that enhances the severity of the disease, and delayed recovery time and increase viral load across time.

Children who were CPT non-users increased the hazards of anemia 2.2 times than those who had those CPT users. A study conducted in Ethiopia revealed that CPT non-users anemia is an independent predictor of anemia [13]. Moreover, the median survival time of free from anemia was significantly shorter in persons with CPT non-users. Indeed, CPT can prevent or reduce the occurrence of opportunistic infection and further complication, therefore, it is important to increase the immune status of the children to decrease viral replication which increases their survival rate by preventing and treating OI infection of which is supported, by a study conducted northwest Ethiopia [50]. CPT prophylaxis has been recommended for the benefit of HIV/AIDS-infected individuals to prevent opportunistic infection since it is a simple and effective intervention to reduce morbidity and to improve quality of life [51]. Besides, children presenting with a poor level of adherence have increased the hazard of anemia by 2.4 times as compared to 
Table 3 Bivariable and multivariable Cox-regression analysis of predictors for anemia among children living with HIV at Debre Tabor and university of Gondar compressive specialized hospitals, Northwest, Ethiopia $2020(n=357)$

\begin{tabular}{|c|c|c|c|c|c|c|}
\hline \multirow[t]{2}{*}{ Characteristics } & & \multicolumn{2}{|l|}{ Anemic } & \multicolumn{3}{|l|}{$\mathrm{HR}(95 \% \mathrm{Cl})$} \\
\hline & & Yes (58) & No (299) & CHR & AHR & $P$-value \\
\hline \multirow[t]{2}{*}{ Age of the Caregiver's } & $\leq 34$ years & 34 & 182 & $0.9(0.55-1.57)$ & - & \\
\hline & $>34$ years & 24 & 117 & Ref & - & \\
\hline \multirow[t]{2}{*}{ Sex Caregiver's } & Male & 30 & 134 & $1.4(0.83-2.32)$ & $1.3(0.82-2.38)$ & 0.220 \\
\hline & Female & 28 & 165 & Ref & Ref & \\
\hline \multirow[t]{2}{*}{ Age of the child (years) } & $\leq 7$ & 25 & 153 & $0.8(0.45-1.28)$ & - & \\
\hline & $>7$ & 33 & 146 & Ref & - & \\
\hline \multirow[t]{2}{*}{ Sex } & Male & 29 & 155 & $1.0(0.59-1.66)$ & - & \\
\hline & Female & 29 & 144 & Ref & - & \\
\hline \multirow[t]{2}{*}{ Residence } & Rural & 10 & 62 & $0.8(0.45-1.75)$ & - & \\
\hline & Urban & 48 & 237 & Ref & - & \\
\hline \multirow[t]{3}{*}{ Marital status } & Married & 39 & 210 & $0.9(0.49-1.70)$ & - & \\
\hline & Divorced & 5 & 32 & $0.7(0.27-2.09)$ & - & \\
\hline & Widowed & 14 & 57 & $0.8(0.34-2.41)$ & - & \\
\hline \multirow[t]{3}{*}{ Religion } & Orthodox & 49 & 253 & $1.4(0.18-10.8)$ & - & \\
\hline & Muslim & 8 & 41 & $1.3(0.16-11.3)$ & - & \\
\hline & Other ${ }^{a}$ & 1 & 5 & Ref & - & \\
\hline \multirow[t]{4}{*}{ Caregiver's educational status } & No education & 25 & 122 & $0.7(0.28-1.89)$ & - & \\
\hline & Primary education & 15 & 77 & $0.6(0.23-1.77)$ & - & \\
\hline & Secondary education & 13 & 83 & $0.6(0.20-1.55)$ & - & \\
\hline & Tertiary education & 5 & 17 & Ref & - & \\
\hline \multirow[t]{2}{*}{ Occupation of the caregiver } & Non employed & 37 & 156 & $1.6(0.94-2.76)$ & $2.1(0.97-3.89)$ & 0.056 \\
\hline & Employed & 21 & 143 & Ref & Ref & \\
\hline \multirow[t]{2}{*}{ Weight for height } & Normal & 21 & 154 & Ref & Ref & \\
\hline & Underweight & 37 & 145 & $1.9(1.10-3.24)$ & $1.5(0.88-2.72)$ & 0.127 \\
\hline \multirow[t]{2}{*}{ Height for age } & Normal & 28 & 183 & Ref & Ref & \\
\hline & Stunted & 30 & 116 & $1.5(0.92-2.59)$ & 1.2(0.69-2.05) & 0.543 \\
\hline \multirow[t]{2}{*}{ CD4 counts or $\%$} & Below threshold & 21 & 49 & $2.4(1.39-4.09)$ & $1.9(1.09-3.37)$ & 0.024 \\
\hline & Above threshold & 37 & 250 & Ref & Ref & \\
\hline \multirow[t]{2}{*}{ WHO stages } & Stage I\&\| & 24 & 220 & Ref & & \\
\hline & Stage III\&IV & 34 & 77 & $4.3(2.50-7.24)$ & $4.2(1.8-11.1)$ & $0.001^{b}$ \\
\hline \multirow[t]{2}{*}{ Hx of opportunistic infections } & No & 17 & 159 & Ref & Ref & \\
\hline & Yes & 41 & 140 & $2.7(1.56-4.85)$ & $1.1(0.45-2.85)$ & 0.800 \\
\hline \multirow[t]{2}{*}{ Regimen at baseline } & AZT-based & 52 & 257 & $1.4(0.60-3.24)$ & - & \\
\hline & d4T-based & 6 & 42 & Ref & - & \\
\hline \multirow{4}{*}{$\begin{array}{l}\text { Cotrimoxazole preventive therapy (CPT) } \\
\text { Isoniazid preventive therapy (IPT) }\end{array}$} & No & 22 & 44 & $3.1(1.82-5.32)$ & $2.2(1.23-3.82)$ & $0.008^{b}$ \\
\hline & Yes & 36 & 255 & Ref & Ref & \\
\hline & No & 40 & 208 & $1.0(0.55-1.72)$ & - & \\
\hline & Yes & 18 & 91 & Ref & - & \\
\hline \multirow[t]{3}{*}{ ART adherence } & Good & 39 & 241 & Ref & Ref & \\
\hline & Fair & 9 & 22 & $4.3(2.02-8.98)$ & $2.0(0.88-4.79)$ & 0.094 \\
\hline & Poor & 12 & 36 & $2.8(1.45-5.37)$ & $2.4(1.20-4.85)$ & $0.016^{\mathrm{a}}$ \\
\hline Treatment failure & Yes & 5 & 31 & $1.0(0.38-2.42)$ & - & \\
\hline
\end{tabular}


Table 3 Bivariable and multivariable Cox-regression analysis of predictors for anemia among children living with HIV at Debre Tabor and university of Gondar compressive specialized hospitals, Northwest, Ethiopia 2020 ( $n=357)$ (Continued)

\begin{tabular}{|c|c|c|c|c|c|c|}
\hline \multirow[t]{2}{*}{ Characteristics } & & \multicolumn{2}{|l|}{ Anemic } & \multicolumn{3}{|l|}{ HR $(95 \% \mathrm{Cl})$} \\
\hline & & Yes (58) & No (299) & CHR & AHR & $P$-value \\
\hline & No & 53 & 268 & Ref & - & \\
\hline \multirow[t]{2}{*}{ TB status } & Yes & 11 & 30 & 2.6(1.34-5.00) & $0.7(0.32-1.53)$ & 0.369 \\
\hline & No & 47 & 269 & Ref & Ref & \\
\hline \multirow[t]{2}{*}{ Duration on ART } & $<=5$ years & 43 & 156 & $1.2(0-3-3.2)$ & - & \\
\hline & $>5$ years & 15 & 143 & Ref & - & \\
\hline \multirow[t]{2}{*}{ ART initiation } & after test and treat & 20 & 134 & Ref & Ref & \\
\hline & before test and treat (pre-ART) & 38 & 165 & $1.5(0.89-2.62)$ & $2.0(0.98-3.57)$ & 0.057 \\
\hline
\end{tabular}

${ }^{\mathrm{a}}$ Significant at $<0.05 ;{ }^{\mathrm{b}}$ Significant at $<0.01 ; \mathrm{CHR}$ Crude hazard ratio, AHR adjusted hazard ratio, Ref reference category, $\mathrm{Cl}$ confidence interval

children with a good level of adherence. Furthermore, the median survival time to develop anemia was significantly longer in persons with a good level of adherence. This could be explained the poor level of adherence has been shown to influence the natural history of HIV disease by accelerating the rate of disease progression, opportunistic infection, and mortality. Moreover, counselling about the importance of adherence has been provided in ART service to prevent opportunistic infection since it is a simple and effective intervention.

This study has some limitations. First, data were collected from routine medical care records and there were limited data on possible predictors of anemia, such as viral load level and psychological support. Second, age, educational, and occupation status of the care givers, as the presence of these variables might be causal for the occurrence of anemia during the initiation of ART.

\section{Conclusion}

The incidence rate of anemia in our retrospective cohort was high. The risk of anemia is present in children living with HIV infection but the risk for anemia is increased based on (WHO clinical staging III and IV, CD4 count below the threshold level, CPT non-users, and poor level of adherence). Since many of these risk factors are present routinely, even within one single patient, our clinical monitoring for anemia quarterly was fully justified as was our routine switch from standard therapies such as AZT to other regimens upon lab confirmation of anemia. Additional methods to improve cotrimoxazole preventative therapy and level of adherence are also needed.

\section{Acknowledgements}

We would like to express our deepest gratitude and appreciation to university of Gondar and Debre Tabor comprehensive specialized hospitals administrators. Likewise, our heartfelt also goes to all individuals who participated in the study, notably ART focal person of the hospitals, and data collectors.

\section{Authors' contributions}

All authors have read and approved the final article. ESC contributed to the conception, study design, data acquisition, data interpretation, and writing of the original article. DGF, SA, FAG, and AT contributed to conception and design, data acquisition, critically revising the article. WAB, AT, YAA, ATA, $\mathrm{DMB}, \mathrm{FTD}$, and $\mathrm{BB}$ contributed to data acquisition, critically revising article and data interpretation.

Funding

This research didn't receive profit.

Availability of data and materials

Data will be had upon request from the corresponding author.

\section{Declarations}

Ethics approval and consent to participate

Ethical clearance was obtained from Debre Tabor University ethical review Committee with Ref NO/HP/842/20 G. C declare that the study is not harm on the study participants. In addition, the ethical review Committee endorsed verbal informed consent must be taken from each study participants. A permission letter was also obtained from each hospital administrators to conducted this study and verbal informed consent was obtained from all the child's caregivers before data collection and the principles expressed in the declaration of Helsinki and good clinical practices.

\section{Consent for publication}

Not applicable.

\section{Competing interests}

The authors have no competing interests to declare.

\section{Author details}

'Department of Pediatrics and Child Health Nursing, College of Health Sciences, Debre Tabor University, Debre Tabor, Ethiopia. ${ }^{2}$ Department of Psychiatry, school of medicine, College of Health Sciences, Debre Tabor University, Debre Tabor, Ethiopia. ${ }^{3}$ Department of Nursing, College of Health Sciences, Wolkitie University, Wolkitie, Ethiopia. ${ }^{4}$ Department of Public health, College of Health Sciences, Debre Tabor University, Debre Tabor, Ethiopia.

${ }^{5}$ Department of Maternal and Neonatal Health Nursing College of Health Science, Debre Tabor University, Debre Tabor, Ethiopia. ${ }^{6}$ Department of Adult health Nursing, College of Health Sciences, Debre Tabor University, Debre Tabor, Ethiopia. ${ }^{7}$ Department of Pediatrics and Child Health Nursing, College of Health Sciences, Debre Birhan University, Debre Birhan, Ethiopia.

${ }^{8}$ Department of Nursing, College of Health Sciences, Woldia University, Woldia, Ethiopia.

Received: 24 December 2020 Accepted: 16 March 2021

Published online: 30 March 2021

\section{References}

1. Beletew B, Mengesha A, Ahmed M, Fitwi A, Wudu M. Determinants of Anemia among HIV-Positive Children on Highly Active Antiretroviral 
Therapy Attending Hospitals of North Wollo Zone, Amhara Region, Ethiopia, 2019: A Case-Control Study. Anemia. 2020;2020. [cited 2020 Jun 15] Available from: https://www.ncbi.nlm.nih.gov/pmc/articles/PMC7049326/

2. Belperio PS, Rhew DC. Prevalence and outcomes of anemia in individuals with human immunodeficiency virus: a systematic review of the literature. Am J Med. 2004;116(7, Supplement 1):27-43.

3. Bunupuradah T, Kariminia A, Chan K-C, Ramautarsing R, Huy BV, Han N, et al. Incidence and predictors of severe anemia in Asian HIV-infected children using first-line antiretroviral therapy. Int J Infect Dis. 2013;17(10): e806-10. https://doi.org/10.1016/ji.jid.2013.04.006.

4. Moore RD, Keruly JC, Chaisson RE. Anemia and survival in HIV infection. JAIDS J Acquir Immune Defic Syndr. 1998;19(1):29-33. https://doi.org/10.1 097/00042560-199809010-00004.

5. (PDF) Anaemia in Developing Countries: Burden and Prospects of Prevention and Control. ResearchGate. [cited 2020 Oct 6] Available from: https://www.researchgate.net/publication/221926480_Anaemia_in_ Developing_Countries_Burden_and_Prospects_of_Prevention_and_Control

6. Akalu TY. Anemia and determinants among severely malnourished children admitted to Amhara regional referral hospitals. Northwest Ethiopia. 2020;2:6.

7. Duffy C, Kenga DB, Gebretsadik T, Maússe FE, Manjate A, Zaqueu E, et al. Multiple concurrent illnesses associated with Anemia in HIV-infected and HIV-exposed uninfected children aged 6-59 months, hospitalized in Mozambique. Am J Trop Med Hyg. 2020;102(3):605-12. https://doi.org/10.42 69/ajtmh.19-0424.

8. Volberding PA, Levine AM, Dieterich D, Mildvan D, Mitsuyasu R, Saag M, et al. Anemia in HIV infection: clinical impact and evidence-based management strategies. Clin Infect Dis Off Publ Infect Dis Soc Am. 2004; 38(10):1454-63. https://doi.org/10.1086/383031.

9. Huibers MHW, Bates I, McKew S, Allain TJ, Coupland SE, Phiri C, et al. Severe anaemia complicating HIV in Malawi; Multiple co-existing aetiologies are associated with high mortality. PLOS ONE. 2020;15(2). [cited 2020 Jun 15] Available from: https://www.ncbi.n/m.nih.gov/pmc/articles/PMC7041863/

10. Quaye W, Addai-Mensah AN. Prevalence of anaemia and immunological markers among Ghanaian HAART-naïve HIV-patients and those on HAART. Afr Health Sci. 2011;11(1). [cited 2020 Jul 23] Available from: https:/www.a jol.info/index.php/ahs/article/view/64985

11. Am L, K B, L M-L, M S, M Y, M A, et al. Prevalence and correlates of anemia in a large cohort of HIV-infected women: Women's Interagency HIV Study. J Acquir Immune Defic Syndr 1999. 2001 Jan 1;26(1):28-35.

12. Bate A, Kimbi HK, Lum E, Lehman LG, Onyoh EF, Ndip LM, et al. Malaria infection and anaemia in HIV-infected children in Mutengene, Southwest Cameroon: a cross-sectional study. BMC Infect Dis. 2016;16. [cited 2020 Jun 15] Available from: https://www.ncbi.nlm.nih.gov/pmc/articles/PMC5041210/

13. Enawgaw B, Alem M, Melku M, Addis Z, Terefe B, Yitayew G. Prevalence and associated risk factors of anemia among HIV infected children attending Gondar university hospital, Northwest Ethiopia: a cross-sectional study. BMC Hematol. 2015;15(1):12. https://doi.org/10.1186/s12878-015-0032-6.

14. Dudu KO, Sagoe KWC, Ayeh-Kumi PF, Affrim RB, Adiku T. The effects of coinfection with human parvovirus B19 and plasmodium falciparum on type and degree of anaemia in Ghanaian children. Asian Pac J Trop Biomed. 2013;3(2):129-39. https://doi.org/10.1016/S2221-1691(13)60037-4.

15. Kothari MT, Coile A, Huestis A, Pullum T, Garrett D, Engmann C. Exploring associations between water, sanitation, and anemia through 47 nationally representative demographic and health surveys. Ann N Y Acad Sci. 2019; 1450(1):249-67. https://doi.org/10.1111/nyas.14109.

16. Molaghan JB, N.P., A.C.R.N.Nov. 1, 1999. The Facts About HIV-Related Anemia. [cited $2020 \mathrm{Jul}$ 23]. Available from: https://www.thebody.com/a rticle/facts-hiv-related-anemia

17. Makubi A, Okuma J, Spiegelman D, Hawkins C, Darling AM, Jackson E, et al. Burden and determinants of severe Anemia among HIV-infected adults: results from a large urban HIV program in Tanzania, East Africa. J Int Assoc Provid AIDS Care JIAPAC. 2015;14(2):148-55. https://doi.org/10.1177/2325957413488195.

18. Geletaw T, Tadesse MZ, Demisse AG. Hematologic abnormalities and associated factors among HIV infected children pre- and post-antiretroviral treatment. North West Ethiopia J Blood Med. 2017;8:99-105. https://doi. org/10.2147/JBM.S137067.

19. Simbauranga RH, Kamugisha E, Hokororo A, Kidenya BR, Makani J. Prevalence and factors associated with severe anaemia amongst under-five children hospitalized at Bugando Medical Centre, Mwanza, Tanzania. BMC Hematol. 2015;15. [cited 2020 Jun 15] Available from: https://www.ncbi.nlm. nih.gov/pmc/articles/PMC4603816/
20. Nyesigire Ruhinda E, Bajunirwe F, Kiwanuka J. Anaemia in HIV-infected children: severity, types and effect on response to HAART. BMC Pediatr. 2012;12(1):170. https://doi.org/10.1186/1471-2431-12-170.

21. Mengistu HM, Taye B, Tsegaye A. Intestinal Parasitosis in Relation to CD4+T Cells Levels and Anemia among HAART Initiated and HAART Naive Pediatric HIV Patients in a Model ART Center in Addis Ababa, Ethiopia. PLoS ONE. 2015;10(2). [cited 2020 Jun 15]Available from: https://www.ncbi.nlm.nih.gov/ pmc/articles/PMC4320101/

22. Mihiretie H, Taye B, Tsegaye A. Magnitude of Anemia and Associated Factors among Pediatric HIV/AIDS Patients Attending Zewditu Memorial Hospital ART Clinic, Addis Ababa, Ethiopia. Vol. 2015, Anemia. Hindawi; 2015. e479329. [cited 2020 Jul 23]. Available from: https://www.hindawi.com/ journals/anemia/2015/479329/

23. Kibaru EG, Nduati $R$, Wamalwa $D$, Kariuki N. Impact of highly active antiretroviral therapy on hematological indices among HIV-1 infected children at Kenyatta National Hospital-Kenya: retrospective study. AIDS Res Ther. 2015;12(1):26. https://doi.org/10.1186/s12981-015-0069-4.

24. Teklemariam Z, Mitiku H, Mesfin F. Prevalence of anemia and nutritional status among HIV-positive children receiving antiretroviral therapy in Harar, eastern Ethiopia. Vol. 7, HIV/AIDS - Research and Palliative Care. Dove Press; 2015:191-6. [cited 2020 Jun 8]. Available from: https://www.dovepress.com/ prevalence-of-anemia-and-nutritional-status-among-hiv-positive-childrepeer-reviewed-fulltext-article-HIV

25. Melkamu MW, Gebeyehu MT, Afenigus AD, Hibstie YT, Temesgen B, Petrucka P, et al. Incidence of common opportunistic infections among HIVinfected children on ART at Debre Markos referral hospital, Northwest Ethiopia: a retrospective cohort study. BMC Infect Dis. 2020;20(1):50 [cited 2020 Oct 7] Available from: https://doi.org/10.1186/s12879-020-4772-y.

26. Fanta TFDR of EM of H. National Guidelines for HIV/AIDS and Nutrition:83.

27. Yihun $B A$, Kibret $G D$, Leshargie $C T$. Incidence and predictors of treatment failure among children on first-line antiretroviral therapy in Amhara region referral hospitals, Northwest Ethiopia 2018: a retrospective study. PLoS One. 2019;14(5):e0215300. https://doi.org/10.1371/journal.pone.0215300.

28. Sibhat $\mathrm{M}$, Kassa M, Gebrehiwot $\mathrm{H}$. Incidence and predictors of treatment failure among children receiving first-line antiretroviral treatment in general hospitals of two zones, Tigray, Ethiopia, 2019. Pediatr Health Med Ther. 2020;11:85-94. https://doi.org/10.2147/PHMT.S243656.

29. WHO issues guidelines on the use of cotrimoxazole prophylaxis. aidsmap. com. [cited 2021 Mar 3]. Available from: https://www.aidsmap.com/news/a ug-2006/who-issues-guidelines-use-cotrimoxazole-prophylaxis

30. Gebresillassie BM, Gebeyehu MB, Abegaz TM, Erku DA, Mekuria AB, Tadesse YD. Evaluation of cotrimoxazole use as a preventive therapy among patients living with HIV/AIDS at Gondar University referral hospital, northwestern Ethiopia: a retrospective cross-sectional study. HIVAIDS Auckl NZ. 2016;8: 125-33.

31. WHO classification system for HIV infection | Training manual | HIV i-Base. [cited 2021 Mar 4]. Available from: https://i-base.info/ttfa/learning-resources/ who-classification-system-for-hiv-infection/

32. Weldearegawi TZ, Gerensea H, Berihu H, Gidey G, Welearegay MZ. The magnitude of opportunistic infections and associated factors in HIV-infected adults on antiretroviral therapy in southern zone Tigray, Ethiopia: a crosssectional study. Pan Afr Med J. 2020;35(126). [cited 2021 Mar 4] Available from: https://www.panafrican-med-journal.com/content/article/35/126/full

33. Melkamu MW, Gebeyehu MT, Afenigus AD, Hibstie YT, Temesgen B, Petrucka $P$, et al. Incidence of common opportunistic infections among HIVinfected children on ART at Debre Markos referral hospital, Northwest Ethiopia: a retrospective cohort study. BMC Infect Dis. 2020;20(1):1-12.

34. Koye DN, Ayele TA, Zeleke BM. Predictors of mortality among children on antiretroviral therapy at a referral hospital. Northwest Ethiopia: a retrospective follows up study BMC Pediatr. 2012;12:161.

35. Wagnew F, Eshetie S, Alebel A, Tesema C, Kibret GD, Gabriel A, et al. Burden of anemia and its association with HAART in HIV infected children in Ethiopia: a systematic review and meta-analysis. BMC Infect Dis. 2019;19(1): $1-9$.

36. Enawgaw B, Alem M, Melku M, Addis Z, Terefe B, Yitayew G. Prevalence and associated risk factors of anemia among HIV infected children attending Gondar university hospital, Northwest Ethiopia: a cross-sectional study. BMC Hematol. 2015;15. [cited 2020 Sep 14] Available from: https://www.ncbi.nlm. nih.gov/pmc/articles/PMC4582838/

37. Abebe M, Alemseged F. Hematologic abnormalities among children on HAART, in Jimma University Specialized Hospital, Southwestern Ethiopia. 
Ethiop J Health Sci. 2009;19(2). [cited 2020 Jul 23] Available from: https:// www.ajol.info/index.php/ejhs/article/view/69420

38. Shet A, Bhavani P, Kumarasamy N, Arumugam K, Poongulali S, Elumalai S, et al. Anemia, diet and therapeutic iron among children living with HIV: a prospective cohort study. BMC Pediatr. 2015;15. [cited 2020 Jun 15] Available from: https://www.ncbi.nlm.nih.gov/pmc/articles/PMC4612411/

39. Ahumareze RE, Rankin J, David A, Wapmuk A, Disu E, Balogun Y, et al. Prevalence of Anaemia and the Relationship between Haemoglobin Concentration and CD4 Count in HIV Positive Children on Highly Active Antiretroviral Therapy (HAART) in Lagos, Nigeria. Curr Pediatr Res. 2016;20(1). [cited 2020 Jun 8] Available from: https://www.alliedacademies.org/abstract/ prevalence-of-anaemia-and-the-relationship-between-haemoglobinconcentration-and-cd4-count-in-hiv-positive-children-on-highly-acti-4592. html

40. Eley BS, Sive AA, Shuttleworth M, Hussey GD. A prospective, cross-sectional study of anaemia and peripheral iron status in antiretroviral naïve, HIV-1 infected children in Cape Town. South Africa BMC Infect Dis. 2002;2(1):3. https://doi.org/10.1186/1471-2334-2-3.

41. Parbey PA, Tarkang E, Manu E, Amu H, Ayanore MA, Aku FY, et al. Risk Factors of Anaemia among Children under Five Years in the Hohoe Municipality, Ghana: A Case-Control Study. Anemia. 2019;2019. [cited 2020 Jun 15] Available from: https:/www.ncbi.n/m.nih.gov/pmc/articles/PMC6614 984/

42. Ketema T, Bacha K. Plasmodium vivax associated severe malaria complications among children in some malaria-endemic areas of Ethiopia. BMC Public Health. 2013;13(1):637. https://doi.org/10.1186/1471-2458-13-637.

43. Herrador Z, Sordo L, Gadisa E, Buño A, Gómez-Rioja R, Iturzaeta JM, et al. Micronutrient Deficiencies and Related Factors in School-Aged Children in Ethiopia: A Cross-Sectional Study in Libo Kemkem and Fogera Districts, Amhara Regional State. PLoS ONE. 2014;9(12). [cited 2021 Feb 7] Available from: https://www.ncbi.nlm.nih.gov/pmc/articles/PMC4278675/

44. Gebreweld A, Ali N, Ali R, Fisha T. Prevalence of anemia and its associated factors among children under five years of age attending at Guguftu health Centre, south Wollo, Northeast Ethiopia. PLOS ONE. 201;14(7):e0218961. https://doi.org/10.1371/journal.pone.0218961.

45. White NJ. Anaemia and malaria. Malar J. 2018;17(1):371. https://doi.org/10.11 86/s12936-018-2509-9.

46. What Is Malaria and What Are the Symptoms?. WebMD. [cited 2021 Feb 8]. Available from: https://www.webmd.com/a-to-z-guides/malaria-symptoms

47. Fenta DA, Nuru MM, Yemane T, Asres Y, Wube TB. Anemia and related factors among highly active antiretroviral therapy experienced children in Hawassa comprehensive specialized hospital, southern Ethiopia: emphasis on patient management. Drug Healthc Patient Saf. 2020;12:49-56. https:// doi.org/10.2147/DHPS.S230935.

48. Lumbiganon P, Kosalaraksa P, Bunupuradah T, Boettiger D, Saphonn V, Truong KH, et al. HIV-infected children in the Asia-Pacific region with baseline severe anemia: antiretroviral therapy and outcomes. Asian Biomed. 2017;10(3):229-34.

49. Legason ID, Atiku A, Ssenyonga R, Olupot-Olupot P, Barugahare JB. Prevalence of Anaemia and Associated Risk Factors among Children in North-western Uganda: A Cross-Sectional Study. BMC Hematol. 2017;17:10.

50. Atalell KA, Birhan Tebeje N, Ekubagewargies DT. Survival and predictors of mortality among children co-infected with tuberculosis and human immunodeficiency virus at University of Gondar Comprehensive Specialized Hospital, Northwest Ethiopia. A retrospective follow-up studies. PloS One. 2018;13(5):e0197145.

51. Date AA, Vitoria M, Granich R, Banda M, Fox MY, Gilks C. Implementation of co-trimoxazole prophylaxis and isoniazid preventive therapy for people living with HIV. Bull World Health Organ. 2010;88(4):253-9. https://doi.org/1 0.2471/BLT.09.066522.

\section{Publisher's Note}

Springer Nature remains neutral with regard to jurisdictional claims in published maps and institutional affiliations.

Ready to submit your research? Choose BMC and benefit from:

- fast, convenient online submission

- thorough peer review by experienced researchers in your field

- rapid publication on acceptance

- support for research data, including large and complex data types

- gold Open Access which fosters wider collaboration and increased citations

- maximum visibility for your research: over $100 \mathrm{M}$ website views per year

At BMC, research is always in progress.

Learn more biomedcentral.com/submissions 